\title{
Overview of the Small Aircraft Transportation System Project Four Enabling Operating Capabilities
}

\author{
Sally A. Viken \\ NASA Langley Research Center, Hampton, VA. USA 23681 \\ Frederick M. Brooks ${ }^{\dagger}$ \\ National Consortium for Aviation Mobility, Hampton, VA. USA 23681 \\ and \\ Sally C. Johnson ${ }^{\ddagger}$ \\ NASA Langley Research Center, Hampton, VA. USA 23681
}

\begin{abstract}
It has become evident that our commercial air transportation system is reaching its peak in terms of capacity, with numerous delays in the system and the demand still steadily increasing. NASA, FAA, and the National Consortium for Aviation Mobility (NCAM) have partnered to aid in increasing the mobility throughout the United States through the Small Aircraft Transportation System (SATS) project. The SATS project has been a five-year effort to provide the technical and economic basis for further national investment and policy decisions to support a small aircraft transportation system. The SATS vision is to enable people and goods to have the convenience of on-demand point-to-point travel, anywhere, anytime for both personal and business travel. This vision can be obtained by expanding near all-weather access to more than 3,400 small community airports that are currently under-utilized throughout the United States. SATS has focused its efforts on four key operating capabilities that have addressed new emerging technologies, procedures, and concepts to pave the way for small aircraft to operate in nearly all weather conditions at virtually any runway in the United States. These four key operating capabilities are: Higher Volume Operations at Non-Towered/Non-Radar Airports, En Route Procedures and Systems for Integrated Fleet Operations, Lower Landing Minimums at Minimally Equipped Landing Facilities, and Increased Single Pilot Performance. The SATS project culminated with the 2005 SATS Public Demonstration in Danville, Virginia on June $5^{\text {th }}-7^{\text {th }}$, by showcasing the accomplishments achieved throughout the project and demonstrating that a small aircraft transportation system could be viable. The technologies, procedures, and concepts were successfully demonstrated to show that they were safe, effective, and affordable for small aircraft in near all weather conditions. The focus of this paper is to provide an overview of the technical and operational feasibility of the four operating capabilities, and explain how they can enable a small aircraft transportation system.
\end{abstract}

\section{Nomenclature}

$A D S-B=$ Automatic Dependent Surveillance-Broadcast

$A M M=$ Airport Management Module

ATC $=$ Air Traffic Control

ATP $\quad=$ Airline Transport Pilot

$C C D=$ Charge-Coupled Device

CDTI = Cockpit Display of Traffic Information

* Technical Assistant to Systems Technology Development Manager, Small Aircraft Transportation System Project, M.S. 916.

${ }^{\dagger}$ NCAM Technical Lead, Small Aircraft Transportation System Project, M.S. 916.

${ }^{\ddagger}$ Branch Head, Crew Systems Branch, M.S. 152. 


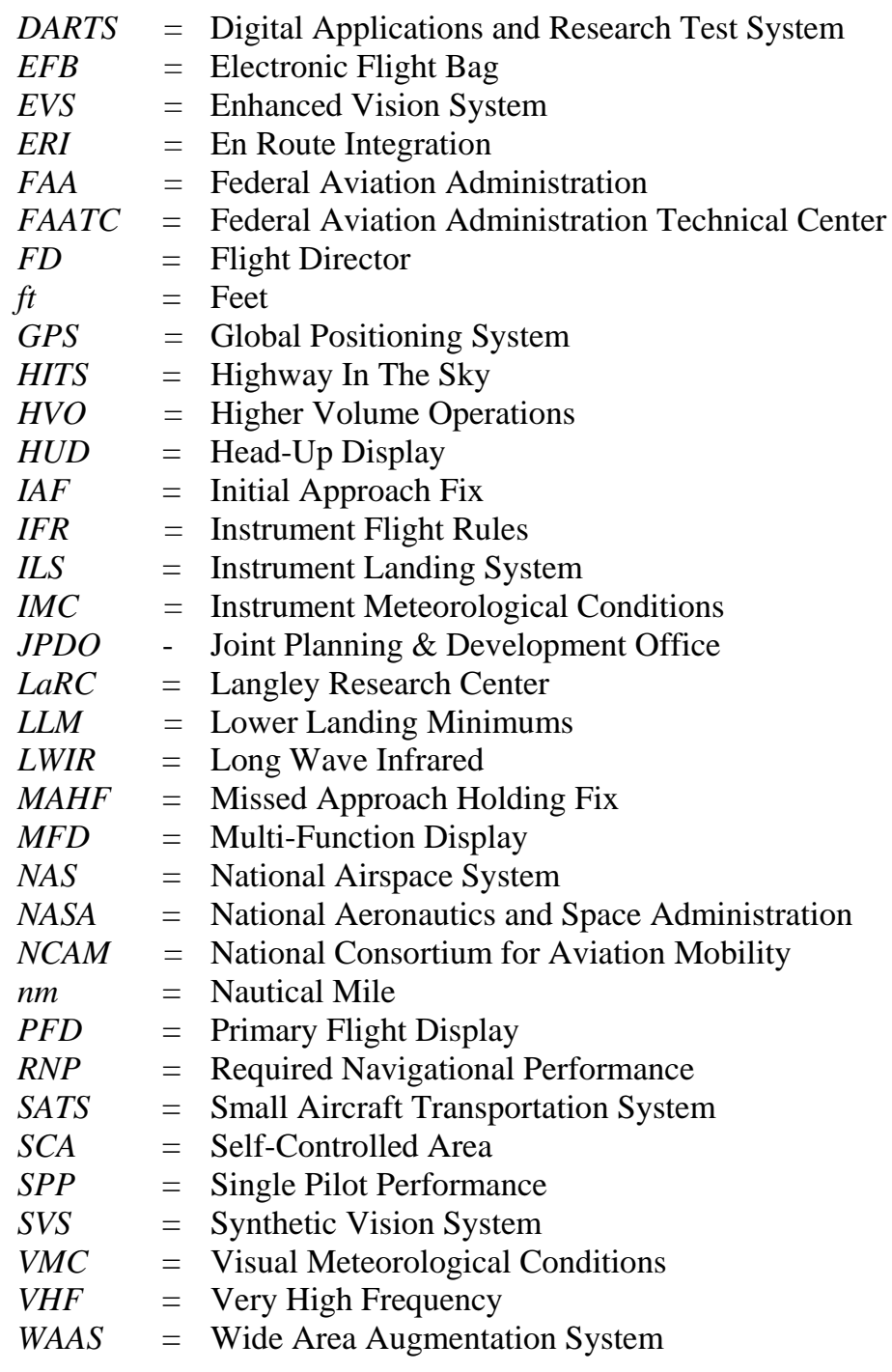

\section{Introduction}

Aviation has become an indispensable part of our nation's transportation system, however, the system as it exists today is reaching full capacity and beginning to limit mobility. In addition, there is a demand in the nation for "more people and goods to travel faster and farther, with fewer delays" as captured in the 2003 NASA Strategic Plan. ${ }^{1}$ Nearly $96 \%$ of domestic air travelers are forced to fly through fewer than 500 airports, and 70\% through fewer than 35 of the Nation's more than 18,000 landing facilities. ${ }^{2}$ Statistics show that $22 \%$ of the population lives within 30 minutes of major/hub airports, $41 \%$ live within 30 minutes of any commercial airport, and $94 \%$ within 30 minutes of small community airports. ${ }^{3}$ One solution to increasing mobility in our nation's transportation system is to exploit the abundant small community airports across the country (figure 1$){ }^{1}$

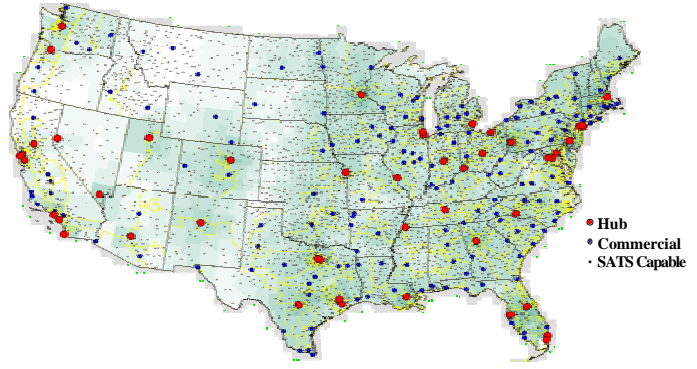

Figure 1. Over 3400 SATS Capable Airports (Public Use, Land-Based, Paved 3000 Ft. Runway Minimum, not a Major Hub).

The SATS vision is to enable people and goods to 
have the convenience of on-demand point-to-point travel, anywhere, anytime for both personal and business travel. The vision can be achieved by expanding near all-weather access to more than 3,400 small community airports (with paved runways 3,000 ft or longer) that are currently under-utilized throughout the United States. Most of these small airports today have no control towers and lie outside air traffic control radar coverage. New and emerging concepts, technologies, and operational procedures need to be developed that will increase the accessibility to these small community airports in near all-weather conditions, with only minimal increase in the ground infrastructure costs. Communities with airports capable of handling small aircraft or micro jets in near all-weather conditions create significant economic opportunities and benefits compared to communities that are not served by such landing facilities. ${ }^{4}$

The SATS project was chartered to demonstrate that new capabilities could be developed which overcome four obstacles to affordable, safe, and reliable on-demand point-to-point air transportation. The SATS project has been a Research \& Technology effort focusing on the four operating capabilities:

- Higher Volume Operations at Non-Towered/Non-Radar Airports;

- $\quad$ En Route Procedures and Systems for Integrated Fleet Operations;

- Lower Landing Minimums at Minimally Equipped Landing Facilities;

- Increased Single Pilot Performance.

These capabilities open the door to a future of personalized air transportation using small aircraft (carrying from four to ten passengers) and small airports to compliment the existing hub-and-spoke system.

The SATS project has been a public-private cost-sharing partnership among NASA, FAA, and the National Consortium for Aviation Mobility (NCAM). NCAM is a consortium of public and private organizations including 130 members of industry, universities, not-for profit organizations, and state aviation authorities located throughout the United States. SATS has leveraged the expertise and capabilities among its partners, and collaborated with other NASA and FAA programs and projects, to enhance the opportunities for technology development, infusion, and transfer, along with information sharing, commercialization, and certification. The NCAM consortium has been structured through six labs: Maryland Mid-Atlantic SATSLab, North Carolina \& Upper Great Plains SATSLab, SouthEast SATSLab, Virginia SATSLab, Michigan SATSLab, and Indiana SATSLab.

The goal of the five-year SATS project has been to take the first steps toward the long-term SATS vision by fostering research and development of primarily key airborne technologies, procedures, and concepts that support the four operating capabilities, providing an integrated technology evaluation and validation, and culminating in a public demonstration to prove that a small transportation system is viable.

\section{Four Enabling Operating Capabilities}

The SATS project has focused its efforts on four enabling operating capabilities that are believed to take a critical step towards the SATS vision of an on-demand, point-to-point air transportation system. These four operating capabilities, that will be further described below, are: Higher Volume Operations (HVO) at NonTowered/Non-Radar Airports where more planes can access the small airports in poor weather conditions; En Route Procedures and Systems for Integrated Fleet Operations (ERI) into the nation's air transportation system; Lower Landing Minimums (LLM) at Minimally Equipped Landing Facilities where planes are less affected by poor visibility; and Increased Single Pilot Performance (SPP) so that the safety and accuracy of pilots are increased.

The project has developed and demonstrated the feasibility of the technologies, procedures, and concepts that support these four operating capabilities through analysis, Human-In-The-Loop simulations, and single and multiaircraft integrated flight evaluations. The simulations and aircraft flight experiments entailed an assessment of the pilot skills (e.g., flight technical error), workload, and situation awareness compared with today's procedures or technologies.

\section{A. Higher Volume Operations at Non-Towered/Non-Radar Airports}

In order to benefit from the go-anywhere, go-anytime, point-to-point air travel, both concepts and procedures need to be developed that will allow for increasing the number of aircraft that can fly in and out of small airports when Instrument Flight Rules (IFR) are in effect. During Instrument Meteorological Conditions (IMC), today's procedural separation operations restrict traffic flow at non-towered/non-radar airports by allowing only one aircraft to fly either an instrument approach or departure at a time. No further operations are allowed into the uncontrolled airspace until the instrument approach or departure is completed, thus leading to significant delays to pilots and passengers if there is increased traffic flow. The SATS project has developed the HVO concept and procedures to overcome this one-in/one-out obstacle (figure 2). This HVO concept is to enable simultaneous operations by 
multiple aircraft in non-radar airspace, at and around small non-towered airports, in near all-weather conditions, through the use of sequencing and self-separation algorithms and flight path management systems ., 2,1

The HVO concept, pioneered at NASA Langley Research Center, is based on two fundamental aspects that include a Self Controlled Area (SCA) and an Airport Management Module (AMM) ${ }^{5,6}$ The SCA is airspace that is established at a SATS-type airport (non-towered/non-radar airport) during IMC in which pilots accept responsibility for maintaining self-separation from other traffic and for following sequencing information on an instrument approach, using procedures and onboard automation (figure 3 ). The AMM is an automated ground computer, located at or near the SATS airport, that provides information regarding the SCA status, and sequence number information to arriving aircraft, along with the 'fix' locations assigned within the SCA. The fix locations include the Initial Approach Fix (IAF) and the Missed Approach Holding Fix (MAHF). These assignments are based on calculations involving aircraft speed, aircraft position [received from aircraft broadcasting state data via Automatic Dependent Surveillance-Broadcast (ADS-B)], and also winds in the terminal area, and missed approach requirements. ${ }^{7}$ The maximum number of aircraft allowed in the SCA is determined by the number of holding altitudes assigned to the IAFs.

SATS aircraft operating within the SCA environment will need to have as a minimum:

- Global Positioning System (GPS) receiver;

- $\quad$ Air-to-Ground Datalink Communications (broadcast and receipt of AMM message);

- Air-to-Air Datalink Communications (broadcast and receipt of ADS-B state messages and procedure intent messages);

- $\quad$ Cockpit Display of Traffic Information (CDTI);

- Software to conduct the HVO procedures (Display of sequencing information from AMM, and Conflict Detection and Alerting Algorithms);

- Voice Communication Radios.

While outside the SCA, the SATS aircraft will operate and

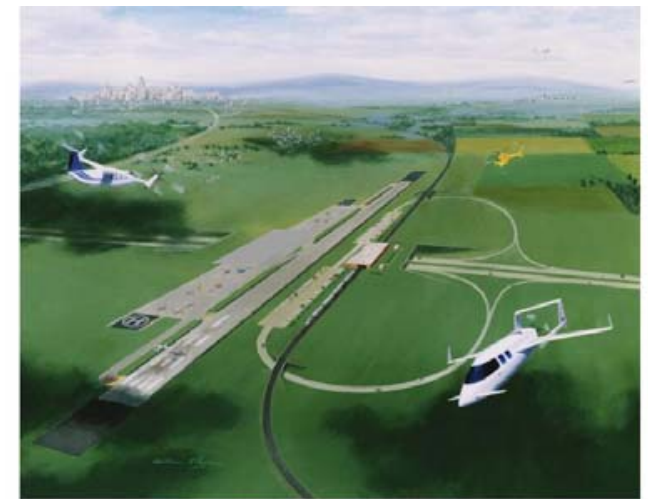

Figure 2. SATS airport concept to allow for simultaneous operations by multiple aircraft at non-towered/non-radar airports in IMC.

interface with Air Traffic Control (ATC) in the same manner as every other IFR aircraft. Prior to departing controlled airspace and entering the SCA, the pilot must send a datalink message to the AMM, requesting entry. The AMM will send a message back to the aircraft whether an entry or standby is granted. The pilot must then contact ATC to get approval to depart controlled airspace, prior to entering the SCA and following the AMM messaging. The SCA will include an instrument approach path, such as a GPS-T, for the pilot to follow. The AMM message will provide information on which aircraft to follow, if more than one HVO equipped aircraft is in the SCA, and which 'fixes' (IAF and MAHF) are assigned to the aircraft. With all HVO participating aircraft broadcasting and receiving critical ADS-B flight information (e.g., position, heading, and airspeed) with other aircraft, all SATS equipped aircraft in the area will be displayed on the CDTI screen along with the pertinent AMM messaging (figure 4). It is the pilot's responsibility to stay a safe distance from other aircraft when in the SCA. Conflict Detection and Alerting algorithms have been developed to warn pilots of any potential conflicts with other aircraft as well as warn pilots if their aircraft is getting off the desired course. When departing a SATS airport, all departure procedures are similar to today's FAA procedures, where the pilot files an IFR flight plan and receives a clearance time from ATC. The pilot can then initiate a departure when the runway is clear, no other aircraft is past the Final Approach Fix, and when he can maintain spacing behind any previously departed aircraft. During Visual Meteorological Conditions (VMC), SATS aircraft will comply with the existing procedures for see-and-avoid to maintain separation from other traffic.

The HVO concept and its procedures have been developed and validated through both simulation and flight tests. The simulations and flight tests have shown that low-time instrument rated pilots could fly the procedures safely, 
proficiently, and with acceptable levels of workload and situation awareness. ${ }^{8,6}$ These results also showed that the volume of aircraft into and out of small airports could increase by four times by following HVO procedures compared to today's procedural separation by air traffic controllers. ${ }^{8}$ This gain can be realized without an increase in workload or complexity. The impact of the HVO concept and procedures not only leads to an increase in mobility, but also a cost savings in fuel by reducing delay time. The HVO concept and procedures can help enable efficient point-to-point travel and allow bypassing of saturated hubs, which could have a significant impact on our transportation system.

Although much progress has been made relative to the HVO concept and procedures, additional research is still required to optimize and assess procedures that could be used in the HVO environment, specifically issues of mixed equipage (both $\mathrm{HVO}$ and non-HVO equipped aircraft flying within the defined SCA) and off-nominal procedures (e.g., emergency landings, cancellation of approach request, and failure of the datalink radio). Pilots of HVO equipped aircraft can only separate themselves from other aircraft broadcasting ADS-B state data. In a worst case scenario, HVO procedures degrade to one-in/one-out procedural separation if limited to one IAF with one holding altitude, or if following a non-HVO equipped aircraft. In terms of off-nominal procedures, reference 9 presents results from selected off-nominal operations researched at NASA Langley Research Center (LaRC), with discussion of further research to be conducted in reference 7 .

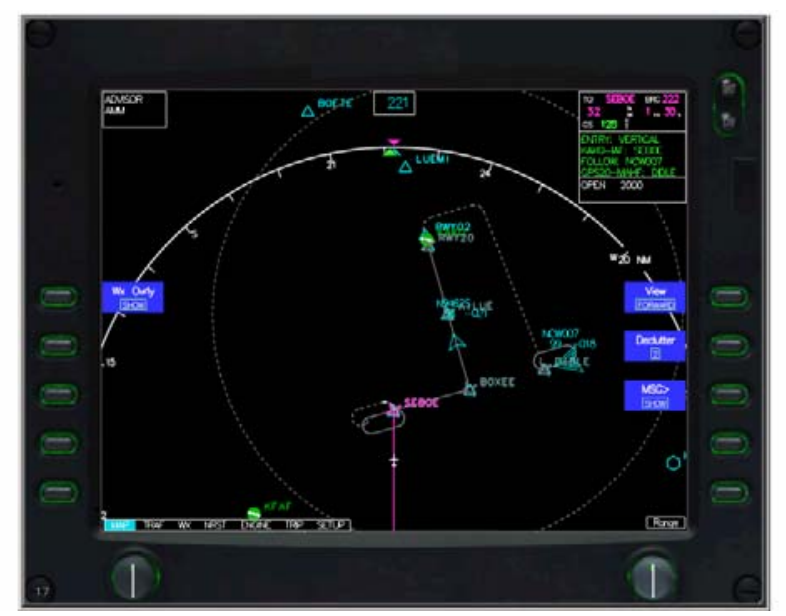

Figure 4. Multi-Function Display showing HVO functionality to the pilot.

\section{B. En Route Procedures and Systems for Integrated Fleet Operations}

In order for SATS to become a viable transportation system, the National Airspace System (NAS) must be able to support the transition of aircraft into and out of the Self Controlled Areas, and also handle the increased point-topoint traffic between small airports. ${ }^{10,11,12}$ This concern has led to the second key operating capability effort, En Route Procedures and Systems for Integrated Fleet Operations (figure 5), otherwise know as ERI, which focuses on two areas:

- Impact mitigation through the development of technologies and procedures to facilitate SATS interaction with the NAS (e.g., transfer of separation responsibility to pilots once inside the SCA, ensuring aircraft departing the SCA are within the acceptance rate for ATC) and working with the FAA to assess operational effectiveness of SATS concepts, technologies, and procedures;

- Traffic modeling to assess the impact of emerging numbers of SATS enabled aircraft on NAS traffic density and flow, project future point-to-point traffic demand triggered by SATS, and assess the ability of the NAS infrastructure to absorb increased traffic. ${ }^{4}$

NASA LaRC and FAA W. J. Hughes Technical Center (FAATC) have worked closely together developing and assessing the language used between the pilots and the controller for entering and exiting the SCA. In addition, proof-of-concept simulation experiments for two east coast regions (which include an en-route sector and a terminal sector) along with a joint FAATC/NASA LaRC simulation (a linked en-route sector) have been conducted. The two east coast regions chosen were the Philadelphia Terminal Radar Approach Control, for its high traffic and complexity, and Danville, Virginia for its relatively low volume and little to no congestion. The simulation experiments included pilots at NASA LaRC and Certified Professional Controllers from both the Philadelphia Terminal Radar Approach Control and Washington Air Route Traffic Control Center. These simulations evaluated the

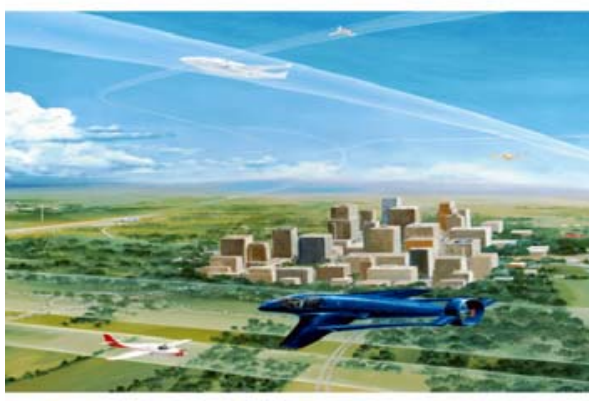

Figure 5. En Route Integration into the NAS.

Air Traffic Controllers acceptability of SATS procedures, their ability to control SATS traffic into and out of the SATS airports, as well as the ability to flow high volumes of SATS equipped aircraft into the NAS (figure 6). These 
simulations were conducted to determine the future feasibility of SATS procedures within the NAS compared to current day one-in/one-out operations. Simulation results into and out of the SCA indicated that SATS would be likely to have minimal or no impact on ATC workload, with the potential to ease future congestion and delays. The preliminary results have determined that the SATS procedures were viable and could prove beneficial for nontowered airports. Most controllers viewed SATS HVO favorably due to the transferring of responsibility from ATC to the flight crew once an aircraft entered the SCA. Issues

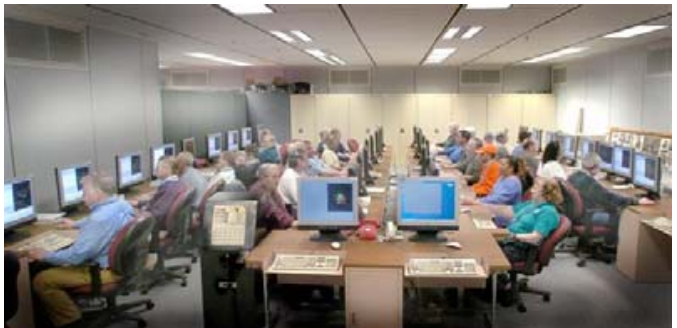

Figure 6. FAATC Target Generation Facility ATC Simulation Pilot Lab. that controllers did note that need to be addressed before the HVO concept could be operationally feasible include: the need to more clearly define roles and responsibilities for ATC and pilots; reduce or tailor size of SCA to specific airspace for which it is sited; refine clearance procedures and phraseology into and out of the SCA; and conduct further investigations on the impact of mixed equipped aircraft (HVO and non-HVO). ${ }^{10}$ The FAAs acceptability of the HVO concept and procedures, along with en route integration into the NAS, plays a critical role in addressing the limitation of one-in/one-out operations at small, community airports in low visibility.

The ERI objective has also involved the development of models and tools to assess the integration of SATSenabled aircraft into en route air traffic flows and controlled airspace. Current NAS simulation and assessment tools do not include SATS operations. Within the SATS project, high fidelity computational tools developed by the 'Transportation Systems Analysis and Assessment' sub-project have created new systems analysis capability for NASA and are currently being used by the Joint Planning and Development Office (JPDO) Evaluation and Analysis Division for prediction of travel demands in the future. SATS demand projections \& tools are being incorporated by the JPDO planners in the development of the Next Generation Air Transportation System. ${ }^{4}$

\section{Lower Landing Minimums at Minimally Equipped Landing Facilities}

For the more than 3400 small SATS capable airports across the United States to be part of a viable transportation system, these airports need reliable and affordable access in near all weather conditions. Analysis conducted within the SATS project has shown that for these small airports (public-use paved runways of $3000 \mathrm{ft}$. or more) across the country, only $20 \%$ have precision instrument approaches. ${ }^{13}$ Current airports without navigation aids and/or instrument approach procedures are limited to VFR minimums for ceiling and visibility, which can be as restrictive as $1000 \mathrm{ft}$. and 3 miles, respectively. ${ }^{14}$ The concept of LLM at Minimally Equipped Landing Facilities is to provide precision approach and landing guidance to small airports in low visibility, through the use of key airborne technologies such as advanced Primary Flight Displays and Multi-Function Displays with graphical flight path guidance [e.g., Highway In The Sky (HITS) and Flight Director (FD) guidance], artificial or enhanced vision, and also Head-Up Displays (HUD) (figure 7).

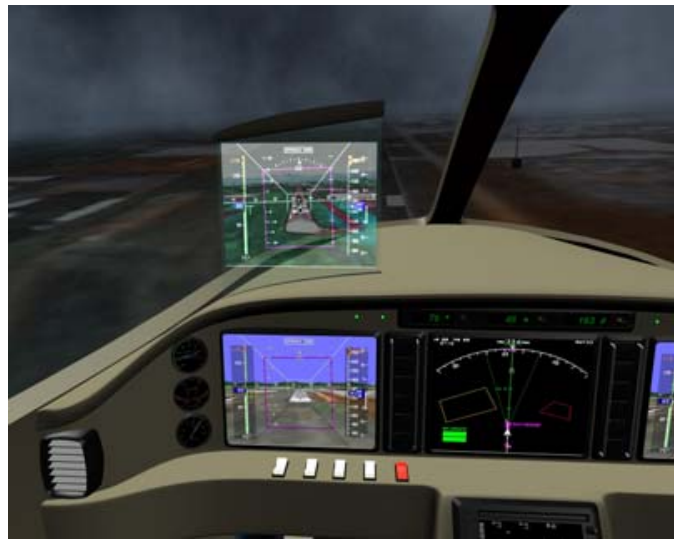

Figure 7. Advanced cockpit concept utilizing a PFD with HITS flightpath guidance, a MFD with navigational tools, and HUD for out-the-window monitoring for improved flightpath accuracy and situation awareness in IMC.
The SATS project has also taken the approach to leverage emerging technologies, such as GPS/Wide Area Augmentation System (WAAS), allowing for lower landing minimums and offsetting additional airport infrastructure costs. Enabling this concept of LLM could avoid land acquisition and approach lighting costs, as well as the high cost for ground-based precision guidance systems such as Instrument Landing Systems (ILS). ${ }^{1}$

The near term goal of SATS is to demonstrate the ability for conducting landings and takeoffs with minimum ceiling and visibility requirements of $200 \mathrm{ft}$. and $1 / 2$ mile, respectively. Early studies in the SATS project showed that if an approach to precision minimums of $200 \mathrm{ft}$. decision altitude and $1 / 2$ mile visibility is made possible, small airports across the United States would be accessible 95\% of the time. ${ }^{15}$ For IMC operations below $200 \mathrm{ft}$., a significant difference in complexity and cost of technologies would be required.

Throughout the project, the SATSLabs have developed and enhanced flight path management displays by 
capitalizing on key airborne technologies that allow pilots to fly en route, approach, and departure procedures much more efficiently and accurately than with conventional instruments, due to the intuitive nature of the displays. SATS has taken advantage of Synthetic Vision Systems (SVS), which rely on navigation information (GPS or GPS/WAAS) and terrain databases to generate a synthetic view of terrain on a Primary Flight Display (PFD) or Multi-Function Display (MFD). ${ }^{16,17}$ One of the goals of the SVS display development efforts is to make IMC operations resemble those conducted in VMC with similar safety and pilot workload. $^{18}$ Research has been conducted by the Virginia SATSLab on guidance displays that incorporate an energy management angle-of-attack Flight Director to aid the pilot in manually flying a safe, accurate, and energy-efficient approach for optimum performance when transitioning between en route and the SATS SCA. ${ }^{19,20}$ North Carolina \& Upper Great Plains

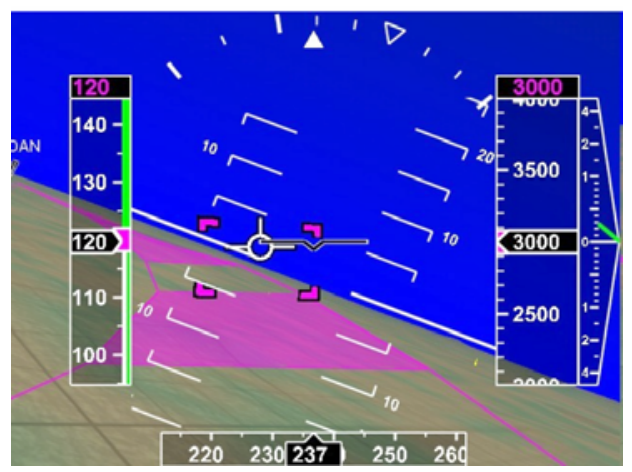

Figure 8. NC\&UGP SATSLab advanced display with SVS/HITS/FD flightpath guidance.

(NC\&UGP) SATSLab has conducted significant work in the area of advanced cockpit displays using synthetic vision, where simulation and flight test results have shown that an aircraft PFD with three-dimensional flight path HITS superimposed on a SVS terrain image provides a viable means for a pilot to confidently and consistently control an aircraft while flying highly accurate precision approaches to a $200 \mathrm{ft}$. decision height in limited visibility (figure 8). ${ }^{21,22}$ The HITS pathway provides a predictive method, rather than reactive method associated with conventional needle and dial instruments, for controlling the aircraft. For simulation and flight instrument approaches to Wakefield Airport in Wakefield, Virginia, the intuitive nature of the SVS/HITS/FD guidance display system provided greater situation awareness, reduced pilot workload, and improved accuracy by 10 -fold over
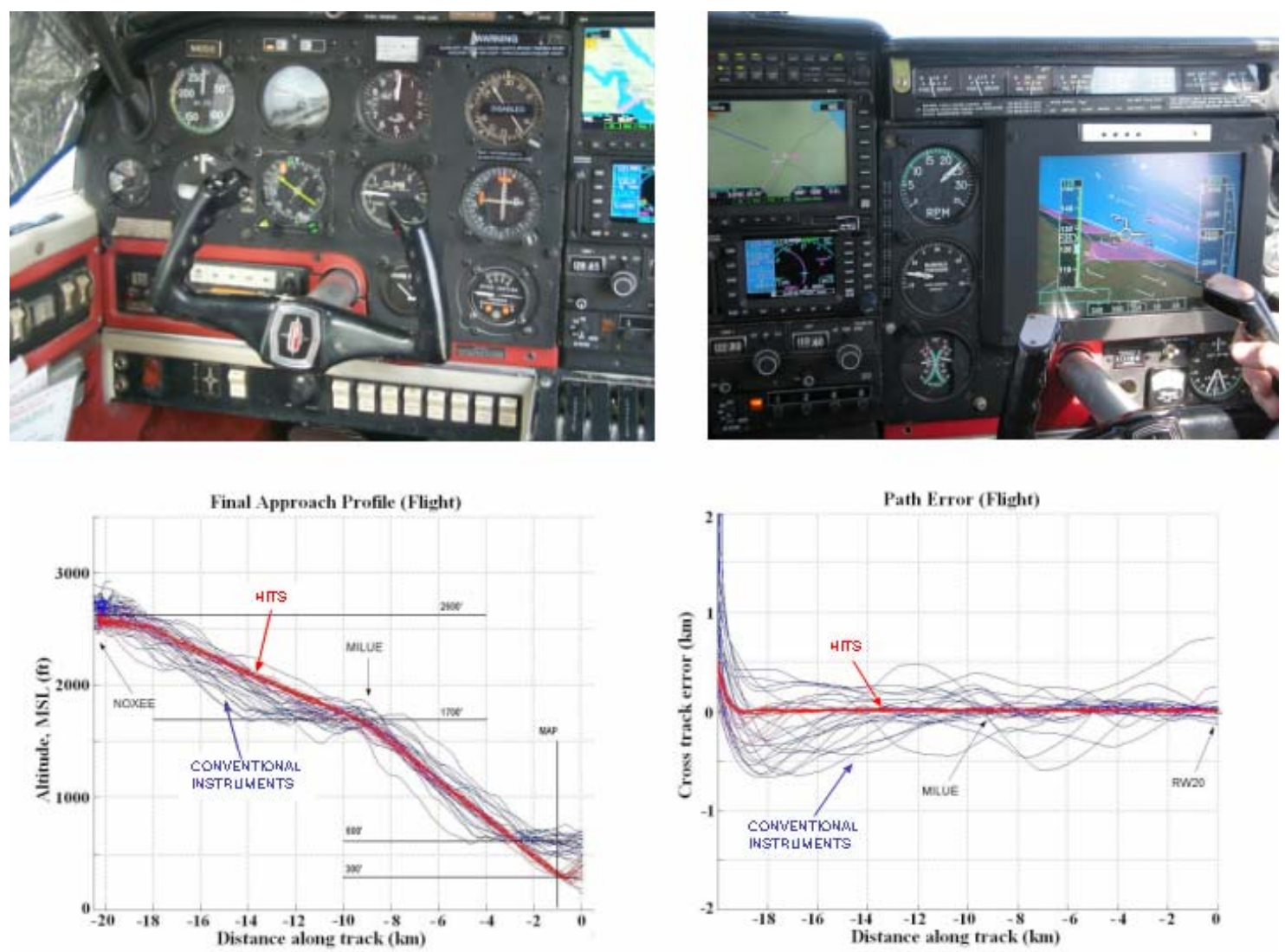

Figure 9. Flight experiment results of flying conventional instrumentation compared with an advanced SVS/HITS/FD guidance display on approaches to Wakefield airport by NC\&UGP SATSLab. 
conventional round dial instrumentation (figure 9). Although the NC\&UGP and other SATSLabs have achieved significant advancements with SVS/HITS, further research, development, and analysis needs to be conducted to prove the level of safety these advanced displays can achieve over conventional flight instrumentation, since currently the FAA limits SVS/HITS displays to current Non-Precision Approach minimums without ILS.

In addition to the SVS effort, low-cost enhanced vision sensors, comprised of a low light level Charge-Coupled Device (CCD) camera and an uncooled Long Wave Infrared (LWIR) imager, have been integrated into a dual-mode system by the SouthEast SATSLab. ${ }^{23,24}$ This dual-mode Enhanced Vision System (EVS) can allow pilots to see at night and enhance visual penetration through low visibility conditions such as rain, haze, and snow, and is compatible with small aircraft/general aviation platforms. The dual-mode system allows for single-aperture imaging and single optical axis with identical field-of-view allowing for easy fusion of both the CCD and LWIR images for enhanced visual performance (figures 10,11). Work has also been conducted on fusing EVS images with a SVS database, allowing pilots to detect obstacles that are not in the terrain database. An added feature of fusing EVS with SVS is that any database inaccuracies due to either GPS/WAAS or database errors can be detected. ${ }^{25}$
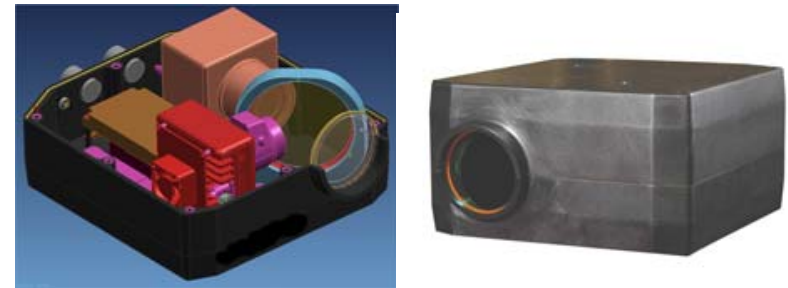

Figure 10. Dual-mode EVS sensor package design.

A significant contribution to the LLM operating capability objective has been the research and development conducted on a low-cost Head-Up Display (HUD) by the Maryland Mid-Atlantic SATSLab. The low cost HUD has been designed to display critical flight performance information along with flight guidance cues to the pilot in a "head up" manner, which is particularly important while on approach to landing during IMC. ${ }^{26,27,28}$ The HUD allows the pilot to maintain outthe-window monitoring, to assist in quickly spotting the runway environment as the aircraft breaks out of the clouds, allowing the pilot safer and more efficient operations over using a Head Down Display (figure 12). The HUD has been developed and tailored for general aviation aircraft to project real-time EVS imagery of the external scenery. A new FAA ruling (Regulation Identification Number 2120-AH78) has approved the operational use of an FAAcertified Enhanced Flight Vision System with a Head-Up Display to allow a pilot to continue the approach from decision height or minimum descent altitude to $100 \mathrm{ft}$. above the touch down zone elevation. ${ }^{29}$ The required visual references of the runway environment or approach light system must be presented on the HUD during the straight in landing instrument approach. This criteria is well within the desired goals of the LLM operating capability of IFR approaches down to $200 \mathrm{ft}$. minimum.

In addition to key airborne technologies developed for the LLM operating capability, SATS has also designed Required Navigational Performance (RNP) based instrument approaches for airports with specific characteristics such as mountainous terrain, restricted airspace constraints, noise abatement restrictions, and shortened approach distances. To achieve these goals, both straight-in and complex curved approaches were demonstrated and evaluated for the approach designs. The complex curved approaches allowed for much more flexible arrival routes with lower landing minimums to the constrained airports. $^{30}$ SATS has used FAA GPS/WAAS approach criteria and modeled approaches to a number of small airports including the GPS-T approach to Danville Regional Airport, in Danville, Virginia where the SATS 2005 Public Demonstration was held. ${ }^{30,31,32}$ The simulated SCA defined for the Danville airport consisted of two initial approach paths merging into a T. A

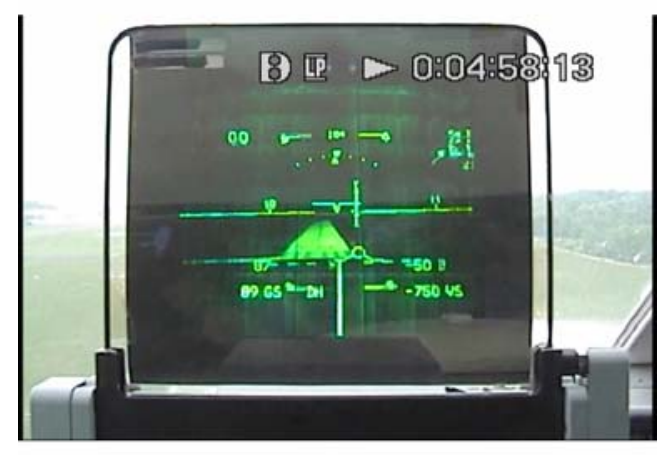

Figure 12. Maryland Mid-Atlantic SATSLab HUD with EVS allows for increased safety and performance on approach to landing. 
SATS GPS-T approach was overlaid on the ILS approach to Runway 02, and also one was overlaid over the certified GPS approach for runway 20 as shown in figure 13.

Flight simulations and flight-testing have proven the feasibility of these approaches. Flight experiments conducted with SATS designed RNP approaches have confirmed RNP performance to well within $+/-0.3 \mathrm{~nm}$. lateral and $+/-125 \mathrm{ft}$. vertical guidance for non-standard approaches, using advanced guidance technologies such as SVS, EVS, HITS, and HUDs. $^{30,21}$ Reference 28 meets this criteria from Final Approach Fix to decision altitude. The RNP 0.3/125 ft. level supports limited Category I minima. ${ }^{33}$

Developing technologies that will improve the pilot's ability to consistently and accurately navigate to a reduced decision height, without the need for costly ground based instrument systems, will greatly improve the ability to achieve near allweather accessibility to small community airports. SATS transportation system studies have shown that the technologies developed for LLM, along with the RNP approach designs, can make access to airports more feasible in spite of restrictions caused by weather, noise abatement, terrain, obstacles, and special use airspace. This will have a significant impact on reducing the number of delays and cancellations, making SATS a significantly more viable transportation alternative.

In fact, system studies have shown that when reliable SATS air-taxi service can be provided at the more than 3400 small airports, there will be a $25 \%$ increase in the total demand for affordable air-taxi service. ${ }^{15}$ In addition, increasing the reliability of accessing small airports with the use of the LLM

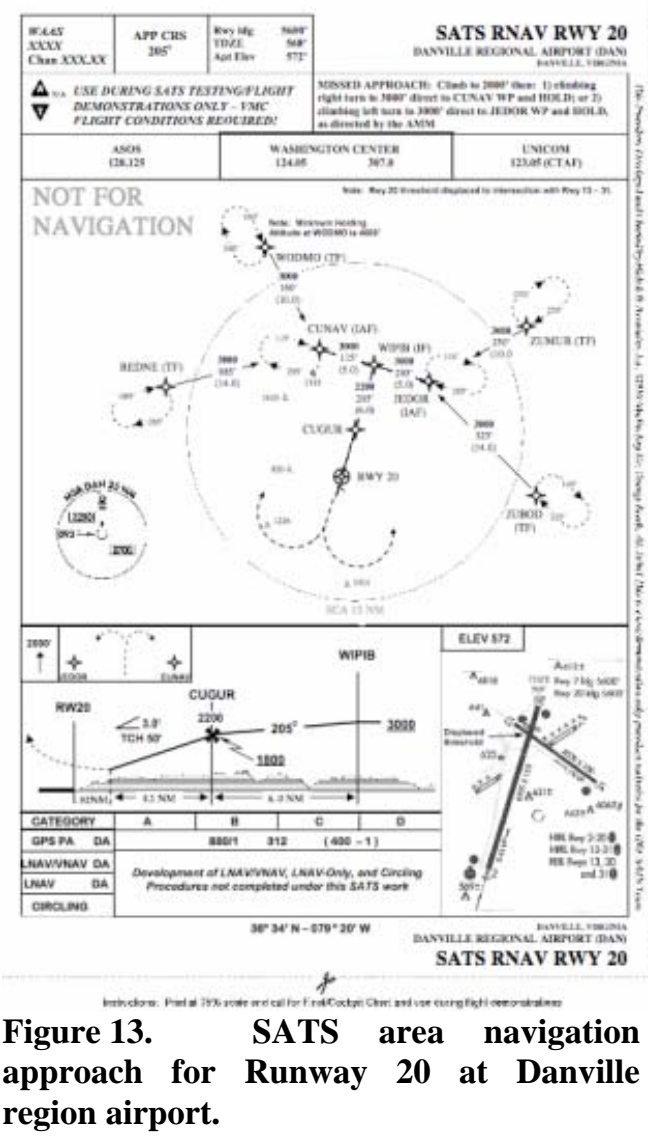
technologies reduces the cost of providing the service. By reducing cancellations and delays the service providers can reduce the cost of the ticket to the traveler by as much as $15 \%$ for terrain challenged regions. ${ }^{34}$

\section{Increased Single Pilot Performance}

The fourth key operating capability of SATS is to increase single pilot safety, precision, and mission completion through the use of human-centered automation. Single pilot performance in IMC can be highly demanding, where visual situation awareness of traffic, terrain, obstructions, and weather can be severely limited. The thrust behind the increased SPP operating capability is to decrease pilot workload while enhancing situation awareness of the environment, resource management, flight planning, and error prevention and tolerance. ${ }^{2}$ This operating capability takes advantage of modern computers to monitor systems and conditions both inside and outside the airplane as well as advanced displays to assist the pilot to make better-informed decisions without overloading him/her with information. Some of the enabling technologies to increase single pilot performance are:

- Advanced displays;

- Integrity monitoring and decision-aiding automation;

- Head-up automation.

These enabling capabilities have largely been integrated with both the HVO and LLM operating capabilities to reduce pilot workload, enhance situation awareness, and offer more intuitive navigation control for improved performance and safety.

SouthEast SATS Lab has conducted simulated flight experiments using advanced display concepts on their SmartDeck system, which provided the pilot with a visual display of the primary flight instrumentation along with the HITS flightpath guidance (figure 14). ${ }^{35}$ SouthEast SATSLab conducted experiments to determine the proportion of low-time instrument rated pilots able to fly at the FAA Airline Transport

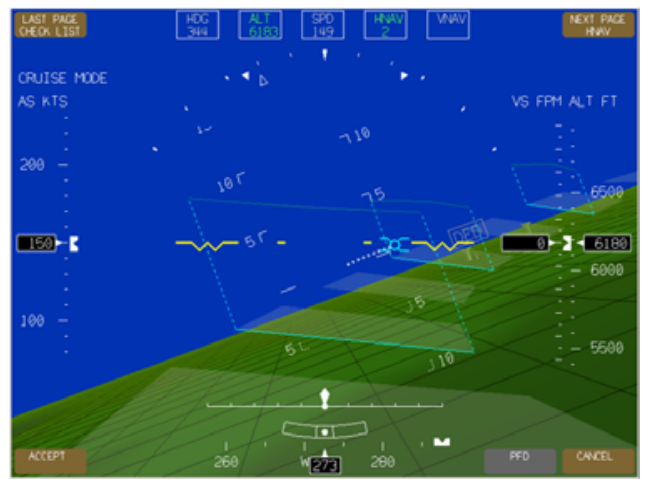

Figure 14. SmartDeck advanced display with SVS/HITS/FD guidance. 
Pilot (ATP) Practical Test Standards using the SmartDeck advanced display system compared to conventional "round dial" instruments on a simulated Cessna 310 platform. Results from the experiment showed that the SmartDeck advanced display with HITS provided enhanced guidance and situation awareness to the low-time single pilots under simulated instrument conditions. The ATP practical test standards were met $78 \%$ of the time with the SmartDeck advanced display on simulated approaches to Daytona Beach airport in Daytona Beach, Florida, as opposed to $55 \%$ of the time using baseline conventional instrumentation. This is a significant improvement over the pilots' performance with today's conventional instruments. In addition to primary flight information provided by the SmartDeck system, the SmartDeck MFD can provide the pilot with moving map displays and automated systems checklists, along with aircraft systems monitoring, such as engine information for early detection and correction of problems if requested.

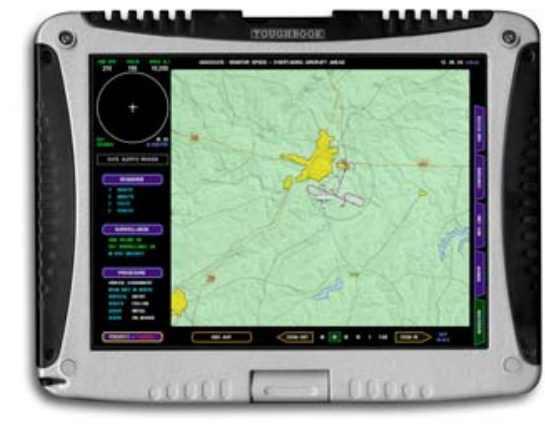

Figure 15. Virginia SATSLab Electronic Flight Bag provides the pilot navigational information and HVO functionality to allow for increased situation awareness and performance.

the EFB and the 'Cockpit Associate' can continuously aid the pilot by conducting situation assessment, conflict detection and alerting, and reporting important notifications, recommendations, and advisories. These decision-aiding devices can lead to improved operational efficiency.

The cockpits of the future may become quite simplified with only a few advanced systems and displays such as these, along with ADS-B and a datalink radio, to meet the flight objectives of the pilots from takeoff to landing. In addition, system studies have determined that single pilot operations can reduce the cost of SATS operations by $16 \%$ compared to dual-pilot operations today. ${ }^{40}$ This cost reduction could be realized when utilizing SATS capability through an air-taxi service. The savings are realized by reducing the costs associated with paying for certified professional pilots. This cost reduction can make the SATS vision more feasible and marketable.

In terms of integrity monitoring and decision-aiding automation, advanced display technologies such as the lowcost Electronic Flight Bag (EFB) and the 'Cockpit Associate', have been developed in the project by the Virginia SATS Lab and the Maryland Mid-Atlantic SATS Lab, respectively. The Virginia SATSLab EFB is a portable electronic device that provides navigation, performance, and safety information, along with flight planning capabilities, weather monitoring, and $\mathrm{HVO}$ functionality to the pilot (figure 15). Flight planning can be conducted from home on the EFB, and then easily transferred to the aircraft for flight navigational operations. ${ }^{36,37}$ The Maryland Mid-Atlantic SATSLab 'Cockpit Associate' is a knowledge-based system designed to simplify the pilot's activities, and report audiovisual alerts on traffic, weather conditions, aircraft health, and approach procedures through the aircraft's audio system and Multi-Function Display (figure 16). ${ }^{38,39,28}$

B

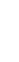

\section{Demonstration of the Four Enabling Operating Capabilities}

The SATS project has been a Research \& Technology activity that has focused its efforts on the four operating capabilities (described above) to strive for an affordable, robust, on-demand, point-to-point air transportation system. The project developed and demonstrated the feasibility of the technologies, procedures, and concepts that support these four operating capabilities through analysis, Human-In-The-Loop simulations, and single and multiaircraft integrated flight evaluations and validations that would ultimately culminate in the 2005 Public Demonstration at Danville, Virginia. In preparation for the public demonstration, integrated multi-aircraft flight 
evaluations and validations were conducted on the four enabling operating capabilities at the Danville Regional Airport, which is a non-towered/non-radar SATS-type airport. Six SATS aircraft participated in the multi-aircraft flight operations at Danville, which included the FAA Technical Center Convair, the NASA Cirrus SR22, the Virginia SATSLab King Air C90, the Maryland Mid-Atlantic SATSLab Cessna 402, the North Carolina \& Upper Great Plains SATSLab Piper Aztec, and the SouthEast SATSLab Cessna 310 (figure 17).

In order to conduct the HVO flight scenario, each SATS aircraft was equipped with:

- $\quad$ GPS receiver;

- GDL-90 Universal Access Transceiver, $978 \mathrm{MHz}$ radio [for Air-to-Air and Air-to-Ground communications];

- $\quad$ Either a Very High Frequency (VHF) Datalink radio or a VHF Long Range Access Point radio [for Air-to-Ground communications];

- CDTI;

- Software to conduct HVO procedures;

- Voice communication radios.

In addition to the equipage for the HVO functionality, each aircraft was also equipped with their specifically developed technologies for the cockpit system architecture to support the LLM and SPP capabilities. This could consist of an advanced cockpit display such as a PFD and MFD with synthetic/enhanced vision system and HITS flightpath guidance, a decision-aiding device, and/or a Head-

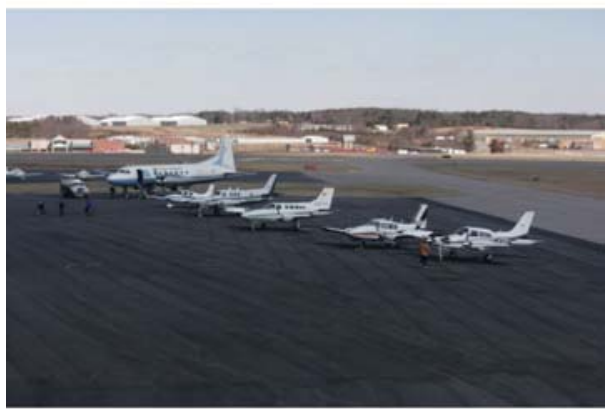

Figure 17. SATS aircraft that participated in the 2005 Public Demonstration. Up Display.

The simulated SCA, designed for the Danville Region airport, was used for the multi-aircraft flight evaluations and validations. The NASA Digital Applications and Research Test System (DARTS) trailer located at the airport, housed the AMM, which received requests and provided the sequencing information to the aircraft via the datalink during the HVO operations. ${ }^{41,42}$ A Ground Based Transceiver received the ADS-B transmissions of aircraft to aircraft "squitter". The Ground Based Transceiver was used to receive aircraft position only. The aircraft position was sent via Local Area Network to the Ground Based Server computer located in the DARTS trailer in order to conduct the AMM assignment operations.

A series of inter-operability flight checkouts were performed at Danville, which entailed conducting datalink communications checkouts between the six SATS HVO equipped aircraft and the ground station. The datalink radios along with the AMM functionality are key in the communications architecture for performing the demonstration of HVO within a SCA around the airport. Evaluations showed that the aircraft could communicate via datalink to the ground station and other SATS participating aircraft necessary to conduct the HVO demonstration at the Danville SCA. The AMM software, which provides the pilot sequencing information into the SCA around the airport, was validated with the ground station and all of the aircraft. Displays located at the ground station and onboard the aircraft showed the SATS traffic and AMM status messaging.

The SATS project culminated with the 2005 SATS Public Demonstration in Danville, Virginia on June $5^{\text {th }}-7^{\text {th }}$, by showcasing the accomplishments achieved throughout the project and proving that a small aircraft transportation system could be feasible. The main tent pavilion was constructed at the south ramp area that housed the technical

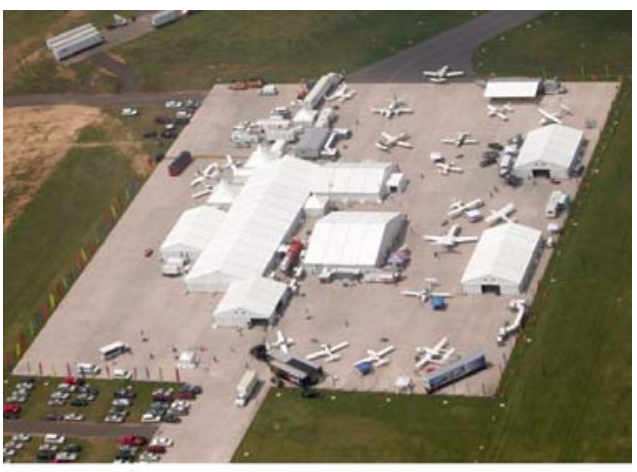

Figure 18. Aerial view of the south ramp area of the Danville Regional Airport where the SATS 2005 Public Demonstration was held. exhibits and hosted live presentations to the audience (figure 18). The Public Demonstration also included projected benefits and impact exhibits, service provider displays, "Day-in-theLife" demonstrations, and education and outreach activities.

During the demonstration, the audience had an opportunity to gain an understanding of the SATS technologies through static displays, simulators, presentations, and a live proof-ofconcept technology flight demonstration. Static displays describing the concepts, technologies, and procedures were organized by operating capability and functionality. Flight simulators were also available to the public to show the intuitiveness and ease of use of the advanced displays, as well as the HVO concept and procedures developed through the project. NASA Langley and the FAA had a live demonstration of their linked HVO simulation experiment also. 
A live proof-of-concept technology flight demonstration of the four operating capabilities was conducted on June $6^{\text {th }}$ and $7^{\text {th }}$ to show their technical and operational feasibility. The flight demonstration focused on how the airspace and the many small and underutilized airports in the United States could be utilized if SATS was implemented. The flight demonstration consisted of the six SATS aircraft flying simultaneous sequenced approaches and landing at the Danville Regional Airport by utilizing a SATS SelfControlled Area, a ground Airport Management Module for aircraft sequencing, and minimal required onboard equipage to maintain self-spacing between participating aircraft. During the flight demonstration, key aspects of the four operating capabilities were showcased. Visitors were able to view a digital depiction of a bird's eye view of the airport and surrounding airspace, tracking all SATS participating aircraft along with any pertinent AMM information (figure 19); cockpit displays; out-the-window or in-cockpit view; and real-time demonstration of flight guidance displays from the participating aircraft. Narrators explained what the aircraft were about to do and directed the audience members to specific features on the screens during the flight demonstration (figure 20).

For the SATS flight demonstration, the SATS GPS-T approach for runway 20 was used (figure 13). During the live demonstration, although it was VMC, it was portrayed to the audience that the scenario being flow was developed for IMC in low visibility, and that the aircraft were handed off from the air traffic controller into the SCA. The six aircraft were stationed outside the SCA near predefined transition fixes prior to the demonstration (REDNE, WODMO, ZUMUR, and JUBOD) (see figure 21). Each aircraft, one by one, sent an entry request to the ground station via datalink. A notification message was received indicating either that

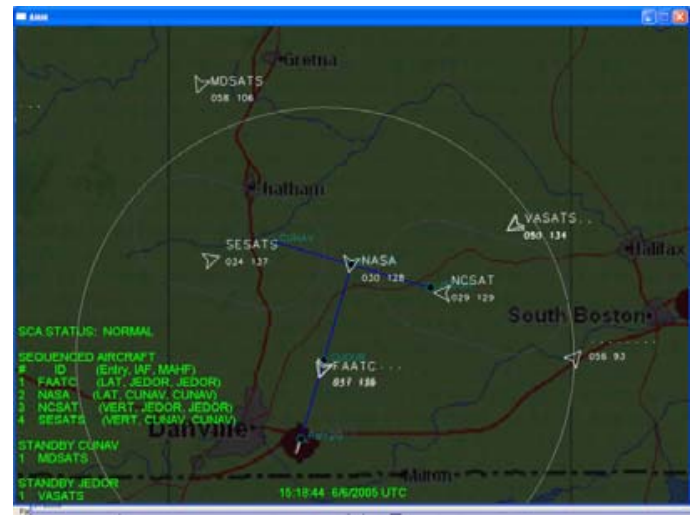

Figure 19. Bird's-eye view of the sixaircraft flight scenario the demonstrated the four enabling operating capabilities.

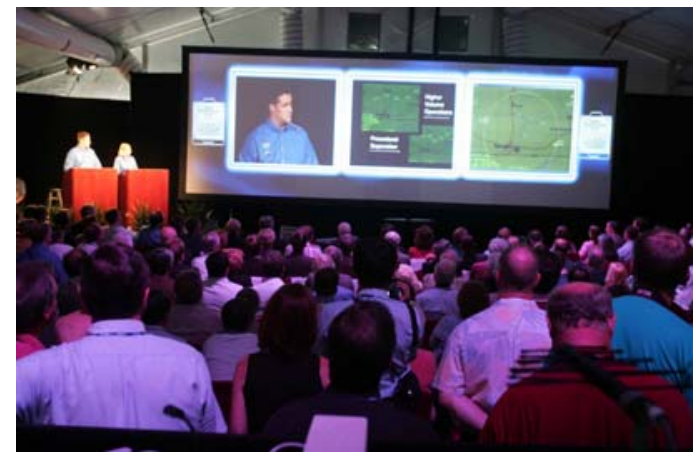

Figure 20. Technical flight demonstration presentation showcasing the four operating capabilities. entry was granted or that standby was necessary (e.g., if SCA was full). The Danville SCA was designed to have up to four aircraft in the SCA at one time. As each aircraft was granted entry into the SCA, the AMM would notify the pilot which aircraft to follow, and their assigned IAF and MAHF. The FAA Convair was the first aircraft to request and be granted entry into the SCA, followed by the NASA Cirrus, North Carolina and Upper Great Plains SATSLab Piper Aztec, SouthEast SATSLab Cessna 310, Virginia SATSLab King Air, and Maryland Mid-Atlantic SATSLab Cessna 402, respectively. During the multi-aircraft flight scenario, both video and data were telemetered from the aircraft to the ground station and transferred to the tent pavilion for the live presentation. The telemetered video and data showcased the labs' and NASA's various technical contributions to the project and the significance to the operating capabilities.

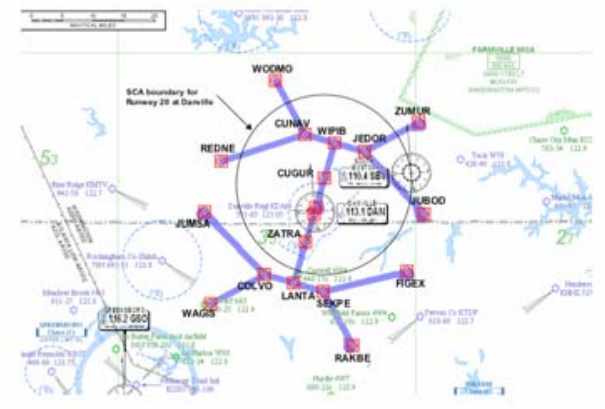

Figure 21. Fix Locations for the Danville SCA with approach to Runway 20.

The multi-aircraft flight scenario flown during the live demonstration confirmed to the audience the viability of the HVO concept, by significantly increasing the operational rate at the non-towered/ non-radar airport using self-separation and sequencing. The datalink communication between the aircraft and AMM ground station was successfully demonstrated by all six aircraft, and HVO functionality was displayed on all aircraft CDTIs. The total time from the first aircraft AMM entry request, from outside the SCA, until all six aircraft had landed was $\sim 31$ minutes in the demonstration. As the SATS aircraft conducted their approach procedures within the SCA, a number of the aircraft showcased their LLM technologies to the audience by demonstrating how the 
pilot could consistently and accurately fly using advanced cockpit displays (such as PFD, MFD, and HUD) with SVS and/or EVS along with HITS guidance, that were programmed for the Danville airport runway. These advanced cockpit display technologies, provided the pilot with a clear view of his current position on the approach to landing, as well as intuitive flightpath guidance for his desired path, allowing for increased accuracy and situation awareness compared to conventional instrumentation in poor weather conditions, without adding additional airport infrastructure. It was also demonstrated that increased single pilot performance could be realized through use of onboard decision-aiding automation tools to assist the pilot throughout all phases of the flight, such as with the EFB and 'Cockpit Associate' to increase situation awareness without additional workload. During the flight scenario, the EFB displayed a moving map showing all aircraft within the SCA including terrain, and weather, along with HVO procedure and safety information. The Cockpit Associate demonstrated the use of an advanced knowledge based processor to infer the needs of the pilot based on the flight plan, traffic conditions, airspace, boundaries, airport status, and weather. The system reminded the pilot of relevant checklists, and kept track of which items had been completed. These tools were demonstrated to show how they could make flying as a single pilot considerably easier.

The outcome of the 2005 demonstration was intended to inspire public understanding, and confidence, in the ability of new aviation technologies to enable the use of smaller aircraft and smaller airports for public transportation. ${ }^{5}$ The technologies, procedures, and concepts were successfully demonstrated to show that they were safe, effective, and affordable for small aircraft use in near all weather conditions. This outreach event attracted the public, NASA and FAA leaders, investors, business executives, congressional leaders, and state and local economic development officials. More than forty-two hundred people attended the event, and many more were reached through the national media coverage that followed.

Transportation engineers at Virginia Tech have predicted up to 15 million SATS passenger-trips/year if an airtaxi service could be provided at a cost of $\$ 1.75$ per passenger-mile in 2010. When SATS technology matures, costs of \$1.25 per passenger mile might be possible increasing the market share to 29 million passenger-trips/year. Today, business passengers traveling in commercial airlines pay $\$ 0.90$ per passenger-mile in a typical 350-mile trip. However, SATS travelers would save an average of 3 hours per trip based on a nationwide analysis. ${ }^{43}$

\section{Summary and Conclusions}

The SATS vision has been to enable people and goods to have the convenience of on-demand point-to-point travel, anywhere, anytime for both personal and business travel, through a network of under-utilized community airports across the nation. The five-year SATS project has been a research and technology development activity, including analysis and assessments, to provide the technical and economic basis for further national investment and policy decisions to support a small aircraft transportation system. The project was conducted through a publicprivate cost-sharing agreement that leveraged the expertise and capabilities of NASA, FAA, and the National Consortium for Aviation Mobility. SATS was chartered to demonstrate that new capabilities could be developed which overcome four obstacles to affordable, safe, and reliable on-demand air transportation. These four key operating capabilities were: Higher Volume Operations at non-towered/non-radar airports; En Route Procedures and Systems for Integrated Fleet Operations; Lower Landing Minimums at Minimally Equipped Landing Facilities; and Increased Single Pilot Performance.

The SATS project culminated in June with the 2005 SATS Public Demonstration at the Danville Regional Airport in Danville, Virginia. The technologies, concepts, and procedures researched and developed throughout the project for the four operating capabilities were demonstrated in the exhibits, presentations, and also the multi-aircraft flight scenario in an integrated manner. Using minimum HVO equipage onboard the aircraft, along with the AMM located at the airport, pilots were able to self-separate to safely perform simultaneous operations in a non-radar environment and sequence themselves into a small airport, significantly increasing the number of operations over today's procedural separation. These HVO procedures were evaluated by the FAA Technical Center for integration of SATS traffic into the NAS. For the LLM operating capability, aircraft-based precision approach and landing guidance displays were demonstrated with advanced cockpit displays and flightpath guidance sufficient for operations with 200-ft ceiling and 1/2-mile visibility without expensive ground infrastructure. For the SPP operating capability, human-centered automation and flight-path guidance were demonstrated to significantly increase flight-path accuracy, situation awareness, and judgment, without increase in workload.

These operating capabilities open the door to a future of personalized air transportation using small aircraft and small airports (many without towers or radar) for improved air mobility and complimenting the existing hub-andspoke system. These capabilities can expand economic development to small communities, improve the productivity throughout the nation, and improve the overall quality of life. SATS has provided a step toward the 
Next Generation Air Transportation System and has demonstrated that there is an exciting future in air transportation.

Further research and analysis will still need to be conducted on the concepts, procedures, and technologies with intentions on proceeding further towards implementation into the NAS and commercialization of products for the aviation community. This research and development is currently being continued within the private sector.

\section{References}

${ }^{1}$ Hefner, J., Airspace Systems Program: Small Aircraft Transportation System (SATS) FY05 Project Plan V 2.0.

${ }^{2}$ NASA Langley Research Center; Small Aircraft Transportation System Program: 2010 Concepts of Operations Document. July 2002.

${ }^{3}$ Team Vision, Southeast SATS Lab Report, SATS Return Investment Study Report, February 2002.

${ }^{4}$ Draft of Annual Congressional Report: NASA Small Aircraft Transportation System Project Status Report, March, 2004 February 2005.

${ }^{5}$ Abbott, T., Jones K., Consiglio, M., Williams, D., Adams, C., “Small Aircraft Transportation System, Higher Volume Operations Concept: Normal Operations.” NASA/TM-2004-213022, August 2004.

${ }^{6}$ Murdoch, J., Ramiscal, E., McNabb, J., Bussink, F., "Small Flight Experiment Investigation of General Aviation SelfSeparation and Sequencing Tasks.” NASA/TP-2005-213539, May 2005.

${ }^{7}$ Baxley, B., Williams, D., Consiglio, M., Adams, C., Abbott, T., “The Small Aircraft Transportation System (SATS) Higher Volume Operations (HVO) Concept and Research”, AIAA 5th Aviation, Technology, Integration, and Operations, September 2628, 2005.

${ }^{8}$ Williams D., Consiglio M., Murdoch J., and Adams C., "Preliminary Validation of the Small Aircraft Transportation Systems Higher Volume Operations (SATS HVO) Concept”, Proceedings of the 24th International Congress of the Aeronautical Sciences, Yokohama, Japan, August 2004.

${ }^{9}$ Baxley, B., Williams, D., Consiglio, M., Conway, S., Adams, C., Abbott, T., “The Small Aircraft Transportation System (SATS) Higher Volume Operations (HVO) Off-Nominal Operations”, AIAA 5th Aviation, Technology, Integration, and Operations Conference, September 26-28, 2005.

${ }^{10}$ Magyarits, S. M., Racine, N. S., Hadley, J. A., Air Traffic Control Feasibility Assessment of Small Aircraft Transportation System (SATS) High Volume Operations (HVO). Final Report. DOT/FAA/CT-05/26, May 2005.

${ }^{11}$ Hadley, J., Racine, N., “Transportation Systems Analysis and Assessment, Small Aircraft Transportation System (SATS) Demonstration. Technical Report.” DOT/FAA/CT. July 2005, (to be published)

${ }^{12}$ William J. Hughes FAA Technical Center, SATS Simulations, Tear Sheet. SATS 2005 Public Demonstration, June 2005.

${ }^{13}$ Hinze, N., Trani, A. A., SATS Airport Set White Paper, VA. Tech. Air Transportation System Lab, June 2004.

${ }^{14}$ Holmes, B. J., Durham, M. H., "Small Aircraft Transportation System Concept and Technologies". Journal of Aircraft, Vol. 41. January-February 2004.

${ }^{15}$ Trani, T., LLM/SPP Meeting, “National Transportation Systems Analysis for the SATS Program”, NCAM, November 2004.

${ }^{16}$ Glaab, L. J., Hughes, M. F., “Terrain Portrayal For Head-Down Displays Flight Test”. $22^{\text {nd }}$ Digital Avionics Systems Conference, October 2003.

${ }^{17}$ Hughes, M. F., Glaab, L. J., “Terrain Portrayal For Head-Down Displays Simulation Results”. $22^{\text {nd }}$ Digital Avionics Systems Conference, October 2003.

${ }^{18}$ Glaab, L. J., "Synthetic Vision Systems General Aviation Equivalent Safety Experiment (SVS-ES)”, NASA LaRC, April 2004.

${ }^{19}$ Old Dominion University, Virginia SATS Lab Report; “Energy Management Guidance Specifications”, June 30, 2004.

${ }^{20}$ Old Dominion University, Virginia SATS Lab Report, "Simulations for RNP Instrument Approach \& Departure and Simulations for Refined Flight Guidance Procedures”, September 30, 2004.

${ }^{21}$ Davis, R. C., Wilt, D. W., Henion, J. T., Alter, K. W., Snow, P., Deaton, J., "Formal Tests For LLM Approaches Using Refined Cockpit Display Technology”. Proceedings of SPIE - The International Society for Optical Engineering, Paper \#580223, Volume 5424, Orlando, Florida, April 2005.

${ }^{22}$ Davis, R. C., Wilt, D. W., Henion, J. T., Alter, K. W., and Snow, P., “Flight Tests for LLM Approaches Using Advanced Cockpit Display Technology”, NASA/NCAM report SL3112D4 \& D5, Hampton, VA. February 2004.

${ }^{23}$ Rand, T. W., Ferrante, R. A., and Suiter, J. M., "Low-Cost, Dual-Mode Enhanced Vision Sensor Prototype”, $24^{\text {th }}$ Digital Avionics Systems Conference, October 31-November 3, 2005, (to be published).

${ }^{24}$ Ferrante, R., and Rand, T., "Visible/Long Wave Infrared Dichroic Beamsplitter”, Journal of Optical Engineering, vol. 44, no. 6, June 2005.

${ }^{25}$ Archer, C., Snow, P., Henion, J., NC\&UGP SATS Lab Report, "Fusing Synthetic Vision Database and Navigation Information with Advanced Sensor Images to Enhance LLM Approaches”, February 27, 2004.

${ }^{26}$ Kollsman Inc., Maryland Mid-Atlantic SATS Lab Report, "System Component Level Specification for Low Cost Head-Up Display”, December 16, 2004.

${ }^{27}$ Kollsman Inc., Maryland Mid-Atlantic SATS Lab Report, “Low Cost Head-Up Display Critical Design Review Results”, December 10, 2004. 
${ }^{28}$ Maryland Mid-Atlantic SATS Laboratory University Research Foundation, "Flight Experiment Results MMSL04016T Final Report”, August 12, 2005.

${ }^{29}$ Federal Register Part II Department of Transportation. Federal Aviation Administration. 14 CFR Parts 1, 91, et al. Enhanced Flight Vision Systems; Final Rule, February 9, 2004.

${ }^{30}$ Alter, K. W., Snow, P., and Davis, R., "Flying Complex Curved RNP Approaches Into North Carolina Airports", NASA/NCAM report SL3112D1, D2 \& D3, Hampton, VA. March 2004.

${ }^{31}$ Hickok, S. M., McConkey, E. D., Maryland Mid-Atlantic SATS Lab Report; "WAAS Approach Procedures for NASA SATS Demonstration at Danville, VA.”, January 6, 2005.

${ }^{32}$ Wilson, I., Embry-Riddle Aeronautical University, SESLC Report, “SATS Airport Experimental RNAV/RNP Procedures”, April 29, 2004.

33 "Criteria for Approval of Category I and Category II Weather Minima for Approach,” Federal Aviation Administration, Advisory Circular 120-29A, August 12, 2002.

${ }^{34}$ RTI International, “MCATS Analyses for Danville and High Impact SATS Markets”. NCAM \#SL05064T, June 272005.

${ }^{35}$ Doherty, S. M., “Single Pilot Performance Study Preliminary Outcome”. SouthEast SATS Lab Consortium, Embry-Riddle Aeronautical University, May 2005, (unpublished).

${ }^{36}$ OPTechnologies, Virginia SATS Lab Report, “SPP Advanced EFB R\&T Systems Development Proactive User-Interfaces for SATS LLM”, August 26, 2004.

${ }^{37}$ Strategic Aeronautics, Virginia SATS Lab Report, “Electronic Flight Bag Software Version 2 (White Paper)”, September 30, 2004.

${ }^{38}$ University Research Foundation Applied Systems Intelligence, Inc., Maryland Mid-Atlantic SATS Lab Report, “Cockpit Associate Knowledge Base Functionality Update Report”, December 7, 2004.

${ }^{39}$ Maryland Mid-Atlantic SATS Laboratory University Research Foundation, "Human-In-The-Loop Cockpit Associate Simulation Experimental Results” MMSL04010T Final Report, March 31, 2005.

${ }^{40}$ RTI International, NC\&UGP SATS Lab, “Trade Study Impact of SATS Technologies”, NCAM \#SL333D, March 2004.

${ }^{41}$ Johnson, S., "Small Aircraft Transportation System Program, 2005 Demonstration Plan”, Revision 1.5, January 2005,

${ }^{42}$ Grube, R., "Preliminary/Critical Review for the Digital Applications and Research Test System”, NASA LaRC, August 11, 2004.

${ }^{43}$ Trani, A. A., Baik, H., "SATS Operations Have Positive National Impact", Volume 1, Number 3, VA. Tech. Air Transportation Systems Lab. Danville 2005 Demonstration, June 2005. 